\title{
Evaluation of the rheological behavior of a semi-solid Al-SiC composite using a parallel-plate drop-forge viscometer
}

\author{
Yasuyoshi Fukui*, Daisaku Nara, Kazuyo Fushimi, Noriyoshi Kumazawa \\ Graduate School of Science and Engineering, Kagoshima University, Kagoshima, Japan
}

Email address:

fukui@mech.kagoshima-u.ac.jp (Y. Fukui),nara@eng.kagoshima-u.ac.jp (D. Nara), fushimi@eng.kagoshima-u.ac.jp (K. Fushimi), kumazawa@mech.kagoshima-u.ac.jp (N. Kumazawa)

\section{To cite this article:}

Yasuyoshi Fukui, Daisaku Nara, Kazuyo Fushimi, Noriyoshi Kumazawa. Evaluation of the Rheological Behavior of a Semi-Solid Al-SiC Composite using a Parallel-Plate Drop-Forge Viscometer. International Journal of Materials Science and Applications.

Vol. 3, No. 6, 2014, pp. 344-352. doi: 10.11648/j.ijmsa.20140306.21

\begin{abstract}
This paper presents of studies performed to assess the effect of rheological behavior on the near-net shape forming of an Al-20 vol\% SiC composite of Duralcan F3A.20S and of the mother aluminum alloy A356 for comparison. Isothermal experiments were conducted using results of a parallel-plate drop-forge viscometer in a temperature range from $849 \mathrm{~K}\left(576{ }^{\circ} \mathrm{C}\right)$ to $862 \mathrm{~K}\left(590^{\circ} \mathrm{C}\right)$. Each experiment indicated that the viscosity decreased in the early increasing shear rate stage and subsequently increased with decreasing shear rate. The overall relationship between the viscosity, $\mu[\mathrm{Pa} \cdot \mathrm{s}]$, and the shear rate, $\dot{\gamma}$ $\left[\mathrm{s}^{-1}\right]$, can be described by a power-law model of $\mu=3.2 \times 10^{7} \dot{\gamma}^{-1.5}$ for Duralcan and $\mu=1.6 \times 10^{7} \dot{\gamma}^{-1.5}$ for A356. The power-law index was the same for both materials, whereas the power-law constant of Duralcan was two times greater than that of the A356 mother alloy because of the distribution of $20 \mathrm{vol} \% \mathrm{SiC}$ particles. The decrease in the viscosity that accompanied an increase in the shear rate depended on both the temperature and the applied force. The viscosities of $32 \mathrm{kPa} \cdot \mathrm{s}$ for both Duralcan and A356 at the maximum effective duration of deformation, which obtained from the plot as a function of the viscosity, appeared to be the points at which the dominant factor governing the visco-plastic flow process transitions from plastic forming to casting. The viscosity must also represent optimum semi-solid forming conditions, as indicated by the achievement of both a moderate working time and an adequate deformation. The optimum operating temperature for both materials can be ranged from $855 \mathrm{~K}$ $\left(582^{\circ} \mathrm{C}\right)$ to $857 \mathrm{~K}\left(584^{\circ} \mathrm{C}\right)$, which is just above the melting point.
\end{abstract}

Keywords: Semi-Solid Forming, Composite Material, Rheology, Visco-Plastic Flow

\section{Introduction}

Semi-solid forming was conceived by Flemings et al. [1] in the early 1970's as a metal forming process for the production of a near-net shape parts. The semi-solid metal forming process can be considered as intermediate between casting and forging (plastic forming) through visco-plastic deformation; the material is worked in a temperature range where solid and liquid were coexisting. The method promises to allow the production of near-net shape parts, thereby combining the advantages of highly complex shapes and the possibility of processing high-strength wrought alloys with excellent mechanical properties [2]. After the work of Flemings et al., a number of authors have investigated the behaviors of semi-solid materials from various viewpoints
[3-7]. Authors have also examined near-net shape forming of $\mathrm{Al}-\mathrm{Al}_{3} \mathrm{Ni}$ and $\mathrm{Al}-\mathrm{Al}_{3} \mathrm{Fe}$ functionally graded materials (FGMs) at temperatures greater than the eutectic melting temperature $[8,9]$.

One of the important properties of semi-solid metals is their ability to flow under the action of applied load. The flow behavior of semi-solid metals is evaluated on the basis of viscosity, which has been measured by various methods $[10,11]$. In general, the viscosity is analyzed under the assumption of a steady-state condition because of the difficulty in measuring the viscosity under a dynamic condition. Data obtained from the steady-state analysis can form the basis of numerical simulations for designing and 
optimizing near-net shape forming processes. In the case of a fast phenomenon, the assumption of a steady-state becomes invalid and will lead to erroneous operation. The problem is broken down by a parallel-plate drop-forge viscometer called the "MIT model", which was developed by Yurko and Flemings [6]. In the MIT model, the top plate of mass for compression is suspended in the furnace and the specimen is compressed at shear rates ranging from $10^{-5}$ to $10^{4} \mathrm{~s}^{-1}$.

The application of semi-solid forming considered in this study is a low-formability material of Al-20 vol \% SiC alloy of Duralcan F3A.20S ${ }^{\mathrm{TM}}$ (delivered from Alcan Asia, Ltd., Japan) which is a kind of particle-distributed composite. To enable the visco-plastic flow analysis of near-net forming of Duralcan F3A.20S, its rheological behavior at high shear rates must be clarified. Moreover, the analysis must be meaningful to confirm the results of semi-solid forming of Al-Al-base intermetallic FGMs reported in our previously papers $[8,9]$. We observed that the semi-solid forming just above the melting point is adequate to obtain finer intermetallics in the Al-base FGMs.

The present work was performed to investigate the rheological behaviors of an $\mathrm{Al}-20$ vol\% $\mathrm{SiC}$ composite of Duralcan F3A.20S. For comparison, the mother aluminum alloy A356 was also examined. The displacement of the cylindrical specimen was measured using a self-made parallel-plate drop-forge viscometer to analyze both the viscosity and shear rate as functions of the duration of deformation. The effect of distributed SiC particles on the rheological properties was evaluated over the temperature range from solid through melting and the optimum semi-solid forming condition was discussed for use in near-net shape forming processes.

\section{Experimental and Analytical Methods}

\subsection{Material and Experimental Apparatus}

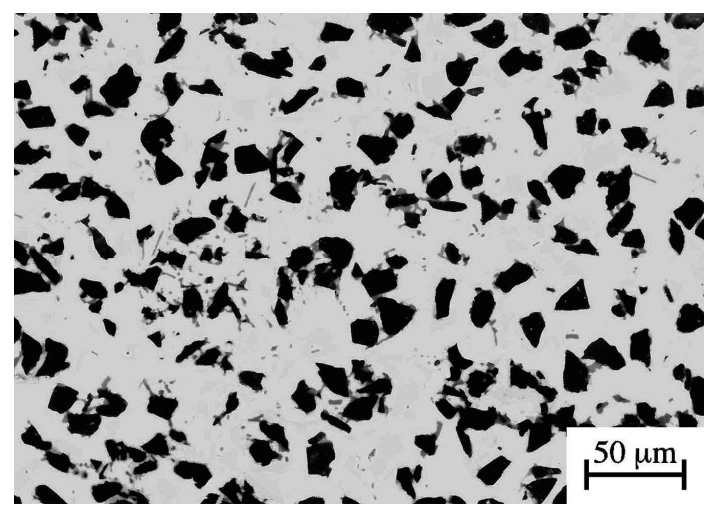

Figure 1. Typical microstructure of Duralcan F3A.20S where black SiC particles are uniformly distributed in the matrix.

The material used in this study was Al-20 vol\% $\mathrm{SiC}$ composite of Duralcan F3A.20S and the commercial purity aluminum alloy A356, which is the mother alloy of Duralcan, was also tested for comparison. Hereafter, these materials are referred to as Duralcan and A356, respectively. Duralcan contains $20 \mathrm{vol} \% \mathrm{SiC}$ particles with a size of \#500 in an A356 matrix; the matrix is a hypoeutectic composition and contains no distributed particles. Fig. 1 shows a typical microstructure of Duralcan where black $\mathrm{SiC}$ spheres are uniformly distributed in the whity hypoeutectic aluminum alloy

matrix. Cylindrical specimens of $20 \mathrm{~mm}$ in diameter $\times 15$ $\mathrm{mm}$ in height were cut from ingots using an electro-discharge machine. The ingot was prepared in advance using hot working to remove the blow holes.

A parallel-plate drop-forge viscometer based on the MIT model was constructed, as illustrated in Fig. 2. The viscometer consists of an electric furnace, a bottom plate, a top plate (weight for compression), a laser sensor, a magnetic chuck, and a computer. The major parts of this viscometer were placed in an electric furnace to allow specimens to be compressed under isothermal conditions. The top plate, which was suspended above the bottom plate in the furnace to compress a specimen using the free-fall weight, was attached to a platen rod to enable adjustment of the falling distance; the position of the top plate was fixed with a magnetic chuck. In contrast, the bottom plate was hollowed out like a container so that the heating wire of the furnace would not be damaged by the scatter of the compressed semi-solid metal.

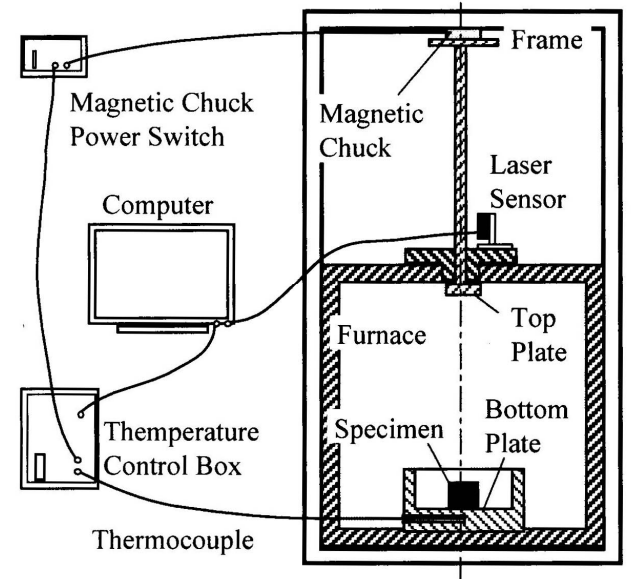

Figure 2. Outline of self-made parallel-plate drop-forge viscometer.

\subsection{Experimental Conditions}

Based on our preliminary experiments involving the backward extruding [8, 9], the test temperatures were selected to fall in a range from $849 \mathrm{~K}\left(576{ }^{\circ} \mathrm{C}\right)$ to $863 \mathrm{~K}(590$ ${ }^{\circ} \mathrm{C}$ ), which ranges from less than to greater than the solidus temperatures of the matrix. The temperature was monitored using the output of a thermocouple inserted into the bottom of the container (i.e., the bottom plate) where the error was within $\pm 2 \mathrm{~K}$. The standard mass of the top plate during free-fall was $7.30 \mathrm{~kg}$; a top plate with a mass of $9.37 \mathrm{~kg}$ was also used to allow a comparison of the effect of applied mass on the test result. The free-fall distance of the top plate for compression was set at $H=30 \mathrm{~cm}$, which enabled a shear rate greater than $10^{4} \mathrm{~s}^{-1}$ to be achieved under the present test 
conditions. These conditions agree with the observation that most commercial processes are conducted at shear rates from $10^{2}$ to $10^{4} \mathrm{~s}^{-1}$ in less than $0.1 \mathrm{~s}$.

The specimen was placed on the center of the bottom plate such that its alignment coincided with the falling axis of the top plate; the specimen was maintained at the test temperature for approximately $30 \mathrm{~min}$. When the magnetic chuck was released, the top plate in free-fall accelerated under gravity and compressed the specimen. The reduction in the specimen height was monitored with a computer through a laser sensor for a period of $2 \mathrm{~s}$ at a sampling time of 0.02 $\mathrm{ms}$. Variation of both the viscosity and shear rate with respect to the duration of deformation was analyzed from the digital data. The effective duration of deformation used for analysis depends on the falling distance, mass of the top plate, and test temperature.

The experiment starts when the top plate begins to free-fall and ends when it comes to rest. The effective digital data are collected in the time interval between the instant when the top plate touches the specimen surface and when it comes to rest. Specifically, the duration of deformation is from the start of deceleration of the top plate to zero speed. However, determining the interval precisely from the experimental data is difficult; therefore, the effective duration of deformation is defined using a two-sided interval estimation, which excludes a few percent of both sides of the estimated region in the present experiment. We confirmed that this estimation has little effect on the analysis results. The related digital data of the effective compressive displacement and the time were directly used to evaluate the first and the second derivatives of $\mathrm{d} h / \mathrm{d} t$ and $\mathrm{d}^{2} h / \mathrm{d} t^{2}$, respectively, to calculate both the viscosity and shear rate. These calculations will be explained in the following section.

\subsection{Calculations of Viscosity and Shear Rate}

In the case of a parallel-plate drop-forge viscometer, the viscosity is calculated by applying the Stefan equation [12] and by referring to the exposition of Yurko and Flemings [6]. The equation is based on the assumptions that the flow is axisymmetric, the fluid is incompressible, no slip occurs at the contact surface, and all of the volume of the specimen remains within the top and bottom plates. A cylindrical coordinate system $(r, \theta, z)$ with an origin of $z$-up being at the bottom center of the cylindrical specimen is used.

When the cylindrical specimen is compressed under pressure, $P$, and with velocity, $v$, the equation of motion and the condition of continuity are reduced to

$$
\begin{gathered}
\frac{\partial P}{\partial r}=\mu \frac{\partial^{2} v_{r}}{\partial z^{2}}, \\
\frac{1}{r} \frac{\partial}{\partial r}\left(r v_{\mathrm{r}}\right)+\frac{\partial v_{z}}{\partial z}=0,
\end{gathered}
$$

where $\mu$ is the viscosity, $v_{r}$ and $v_{z}$ are the velocity components of directions $r$ and $z$, respectively. From the relations (1) and (2), the Stefan equation is given as

$$
F=-\frac{3 \mu V^{2}}{2 \pi h^{5}}\left(\frac{\mathrm{d} h}{\mathrm{~d} t}\right)
$$

where $F$ is the force applied to the specimen, $V$ is the volume of the specimen, and $h$ is the height of the specimen at time $t$.

In the parallel-plate drop-forge viscometer, considering the velocity and acceleration of the top plate, a balance of the applied force and the viscous force of the specimen is reduced to the following equation

$$
m_{p}\left(g+\frac{\mathrm{d}^{2} h}{\mathrm{~d} t^{2}}\right)=-\frac{3 \mu V^{2}}{2 \pi h^{5}}\left(\frac{\mathrm{d} h}{\mathrm{~d} t}\right)
$$

where $m_{\mathrm{p}}$ is the mass of the top plate, and $g$ is the acceleration due to gravity. From (4), the instantaneous volume-averaged value of viscosity is given as

$$
\mu=-2 m_{p} h^{5}\left(g+\frac{\mathrm{d}^{2} h}{\mathrm{~d} t^{2}}\right) /\left(3 \pi R_{0}^{4} h_{0}^{2} \frac{\mathrm{d} h}{\mathrm{~d} t}\right) .
$$

The first and second derivatives, $\mathrm{d} h / \mathrm{d} t$ and $\mathrm{d}^{2} h / \mathrm{d} t^{2}$, respectively, are obtained directly from the relationship between displacement and time data. The viscosity is then calculated as a function of time.

The shear rate, $\dot{\gamma}$, of a cylindrical specimen, which is assumed to be a Newtonian fluid, under compression is given by

$$
\dot{\gamma}=-\frac{6 r z}{h^{3}} \frac{\mathrm{d} h}{\mathrm{~d} t} .
$$

The volume-averaged shear rate, $\dot{\gamma}_{a v}$, is then given as

$$
\dot{\gamma}_{a v}=\frac{2 \pi}{V} \int_{0}^{R} \int_{0}^{h / 2} \dot{\gamma} r \mathrm{~d} z \mathrm{~d} r=-\frac{R}{2 h^{2}} \frac{\mathrm{d} h}{\mathrm{~d} t},
$$

where $R$ is the outer radius of the specimen at time $t$, which can be calculated from the constant-volume condition. Hereafter, (7) of the instantaneous volume-averaged value is used to evaluate shear rate.

\section{Results and Discussion}

\subsection{Features of Pressed Specimens}

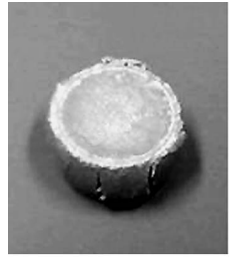

(a) $851 \mathrm{~K}$

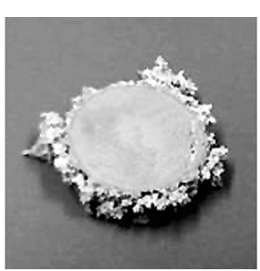

(b) $855 \mathrm{~K}$

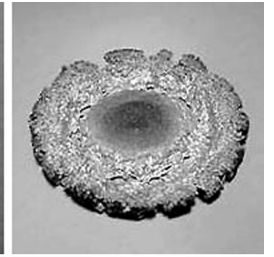

(c) $859 \mathrm{~K}$
Figure 3. The profiles of compressed Duralcan F3A.20S specimen in the drop-forge viscometer. Applied plate mass is the standard value of $7.30 \mathrm{~kg}$.

Typical profiles of the Duralcan specimens after the experiments are shown in Fig. 3. These profiles indicate that the deformation was nearly homogeneous when the potential energy of the top plate was converted into kinetic energy and 
supplied to the specimen. In Fig. 3 (a), external and longitudinal cracks are observed over the midheight of the side surface of the specimen at $851 \mathrm{~K}\left(578{ }^{\circ} \mathrm{C}\right)$. This observation indicates that the matrix does not behave as a semi-solid material. In contrast, no crack was observed in the specimen tested at $855 \mathrm{~K}\left(582{ }^{\circ} \mathrm{C}\right)$, as shown in Fig. 3 (b). This result suggests that the specimen was compressed uniformly under

semi-solid conditions. We also observed that aluminum melt seeped through the gaps among solid particles and then solidified in the form of drops. No cracking was observed in the specimen tested at $859 \mathrm{~K}\left(586{ }^{\circ} \mathrm{C}\right)$, as shown in Fig. 3 (c). These result indicate that the compressed material was scattered in all directions and collided with the wall of the bottom plate which was hollowed out like a container.

The features of the compressed specimens indicate that measurement of viscous data at test temperatures below $851 \mathrm{~K}$ $\left(578{ }^{\circ} \mathrm{C}\right)$ was not possible, because the test conditions were almost the same as those induced by uniaxial compression under hot working conditions associated with little deformation. In contrast, the effective duration of deformation at temperatures beyond $859 \mathrm{~K}\left(586{ }^{\circ} \mathrm{C}\right)$ was in the range from 0.2 to $0.6 \mathrm{~ms}$ and the corresponding sampling points were from 10 to 30 points, which indicated that the tests at temperatures beyond $859 \mathrm{~K}\left(586^{\circ} \mathrm{C}\right)$ were not satisfactory for obtaining the derivatives needed to calculate the viscosity. Moreover, the estimated maximum shear rate of $3 \times 10^{4} \mathrm{~s}^{-1}$ and the minimum viscosity of a few $\mathrm{Pa} \cdot \mathrm{s}$ appeared to be meaningless extreme values. Thus the appropriate test temperature under the present conditions was confirmed to be in a range from approximately $855 \mathrm{~K}\left(582{ }^{\circ} \mathrm{C}\right)$ to $857 \mathrm{~K}(584$ $\left.{ }^{\circ} \mathrm{C}\right)$. Here, the temperature measurement error of $\pm 2 \mathrm{~K}$ appeared to be affected the nominal temperature, however the error did not influence the analytical results because both the viscosity and the shear rate, which were calculated by (5) and (7), respectively, were not functions of the test temperature.

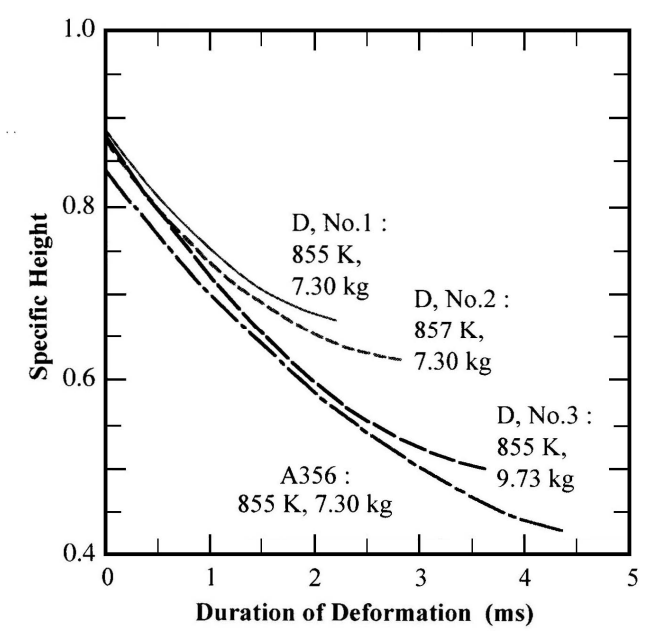

Figure 4. Variation of specific height of $h / h_{o}$ as a function of the duration of deformation for typical comparable experiments. Capital letter $D$ indicate the results of Duralcan F3A.20S.

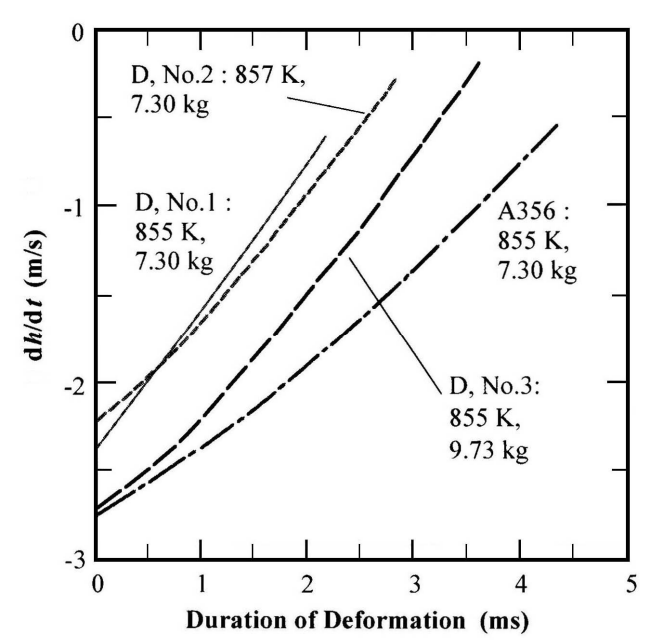

Figure 5. Variation of the first derivatives of $d h / d t$ as a function of the duration of deformation derived from the results shown in Fig.4.

\subsection{Evaluation of Rheological Behavior}

The variations of the viscosity and shear rates were analyzed using the data of effective compressive displacement; typical results are shown in Figs. 4 to 8 . The solid line of "D, No.1" shows the results for Duralcan at a test temperature of $855 \mathrm{~K}\left(582{ }^{\circ} \mathrm{C}\right)$ and under an applied mass of $7.30 \mathrm{~kg}$, which was taken as the standard condition in this experiment. The dotted line of "D, No.2" and the broken line of "D, No.3" shows the results for Duralcan at $857 \mathrm{~K}\left(584{ }^{\circ} \mathrm{C}\right)$ under a $7.30 \mathrm{~kg}$ applied mass and at $855 \mathrm{~K}$ $\left(582{ }^{\circ} \mathrm{C}\right.$ ) under a $9.73 \mathrm{~kg}$ applied mass, respectively. The single dotted line of "A356" shows the results for A356 at a test temperature of $855 \mathrm{~K}\left(582{ }^{\circ} \mathrm{C}\right)$ under an applied mass of $7.30 \mathrm{~kg}$. The results of "D, No.2", "D, No.3", and "A356" are compared with "D, No.1" from the viewpoint of a qualitative evaluation of the effects of the test temperature, applied mass, and dispersed $\mathrm{SiC}$ particles on the viscosity. These experimental conditions are summarized in Table 1.

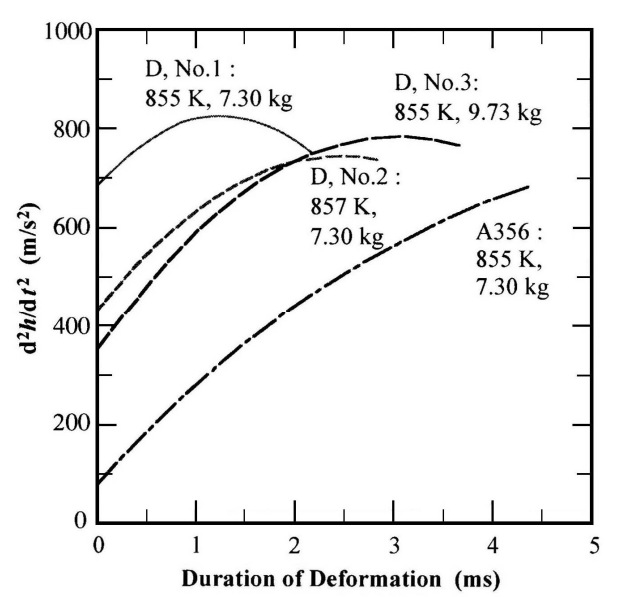

Figure 6. Variation of the second derivatives of $\mathrm{d}^{2} h / \mathrm{d} t^{2}$ as a function of the duration of deformation derived from the results shown in Fig 5. 


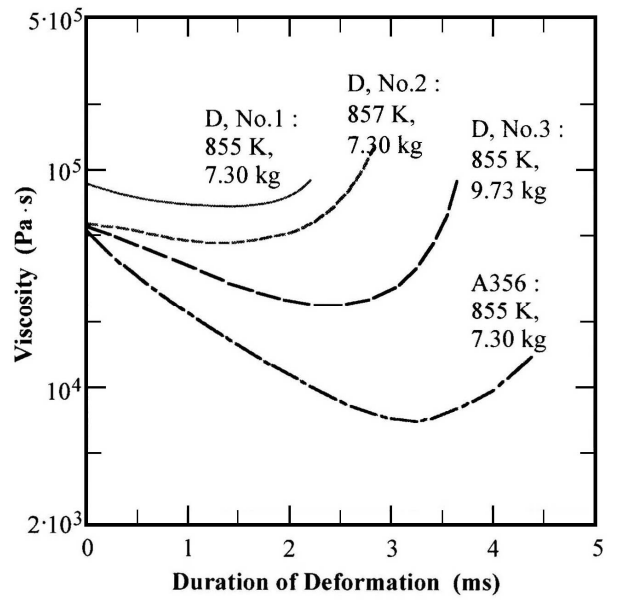

Figure 7. Variation of volume-averaged viscosity calculated by (5) with respect to the duration of deformation.

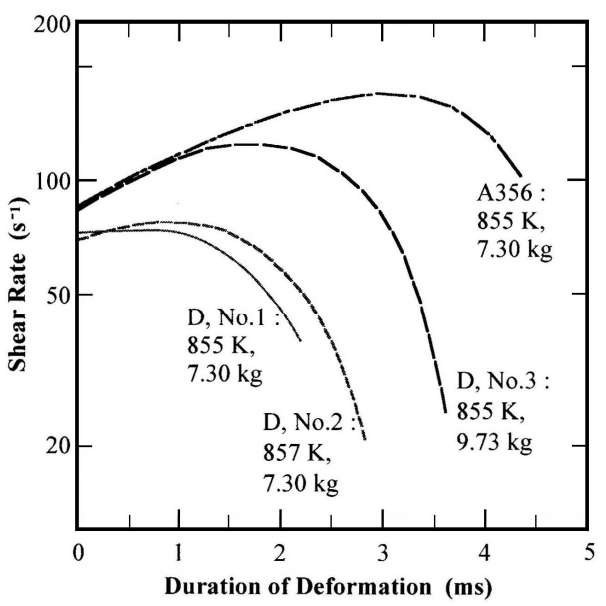

Figure 8. Variation of volume-averaged shear rate calculated by (7) with respect to the duration of deformation.

Table 1. Summary of experimental conditions shown in Fig. 4 to 8.

\begin{tabular}{ccccc}
\hline Specimen & D,No.1 & D,No.2 & D,No.3 & A356 \\
\hline Test Temperature $(\mathrm{K})$ & 855 & 857 & 855 & 855 \\
Test Temperature $\left({ }^{\circ} \mathrm{C}\right)$ & 582 & 584 & 582 & 582 \\
Applied Load $(\mathrm{kg})$ & 7.30 & 7.30 & 9.73 & 7.30 \\
\hline
\end{tabular}

Fig. 4 shows the variation of specific height, $h / h_{0}$, and indicates the tendency of specimen height to decrease with respect to the duration of deformation measured by a laser displacement sensor. Fig. 5 shows the relationship between the instantaneous velocity, i.e., differential coefficient $\mathrm{d} h / \mathrm{d} t$, and the duration of deformation. The velocity decreased toward zero with respect to the duration of deformation. Fig. 6 shows the variation of instantaneous acceleration $\mathrm{d}^{2} h / \mathrm{d} t^{2}$ as a function of the duration of deformation. We observed that the variation of instantaneous acceleration initially increased and then decreased with decreasing compression rate. Fig. 7 shows the relationship between the viscosity and the duration of deformation calculated using (5) on the basis of the results shown in Figs. 4 to 6 . The viscosity initially decreased and then increased with the duration of deformation. Fig. 8 shows the variation of the shear rate as a function of the duration of deformation curves calculated using (7); the curve profiles show the reverse of the trend shown in Fig. 7. According to Figs. 4 to 8 , deformation became easier when the test temperature was increased, mass of compression was increased, or alloys contained no dispersed $\mathrm{SiC}$ particles. The maximum duration of deformation was less than $5 \mathrm{~ms}$ at shear rates in excess of $10^{2} \mathrm{~s}^{-1}$ and was obtained in the case of "A356". The measured viscosities and the shear rates ranged from a few to a half million of $\mathrm{Pa} \cdot \mathrm{s}$ and from several tens to several tens of thousands $\mathrm{s}^{-1}$, respectively.

\subsection{Effect of Distributed Particles on Viscosity}

The relationship between viscosity and shear rate at test temperatures from $855 \mathrm{~K}\left(582{ }^{\circ} \mathrm{C}\right)$ to $857 \mathrm{~K}\left(584{ }^{\circ} \mathrm{C}\right)$ is summarized in Fig. 9 on a double-logarithmic chart. In Fig. 9, the thick lines show the results for Duralcan and the points of minimum viscosity are indicated by filled circles. The results for A356 are illustrated using thin lines and open circles, respectively. The allowed direction indicated the progress of deformation. Drop-forge experiments showed individually that the viscosity decreased in the early increasing shear rate stage and that the viscosity subsequently increased as the shear rate decreased with the release of compression energy supplied by the free-fall top plate. These results indicate that the viscosity increased in accordance with the decrease in the shear rate and that minimum viscosity was achieved at maximum shear rate.

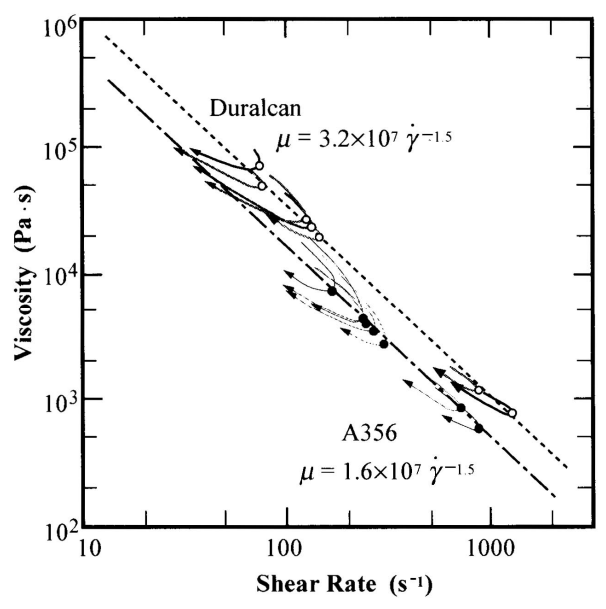

Figure 9. Summary of the viscosity as a function of shear rate. The results of Duralcan F3A.20S (thick line) are compared with those of the mother aluminum alloy A356 (thin line). Plotted point and allow indicate the minimum and the progress of deformation, respectively.

An overall linear relationship on a log graph was established, as shown in Fig. 9. The results indicated that high temperatures and high shear rates were favorable toward overcoming the deformation resistance against the flow of material. The summarized relationship between the viscosity, $\mu[\mathrm{Pa} \cdot \mathrm{s}]$, and the shear rate, $\dot{\gamma}\left[\mathrm{s}^{-1}\right]$, are described by a power-law model 


$$
\mu=3.2 \times 10^{7} \dot{\gamma}^{-1.5}
$$

for Duralcan and

$$
\mu=1.6 \times 10^{7} \dot{\gamma}^{-1.5}
$$

for A356. The power-law indexes were the same for both materials, whereas the power-law constant of Duralcan was two times greater than that of A356 because of the distribution of $20 \mathrm{vol} \% \mathrm{SiC}$ particles.

The viscosities of suspensions containing 10 to $50 \mathrm{vol} \%$ of solid particles were estimated from one of the following equations $[13,14]$;

$$
\begin{gathered}
\mu=\mu_{0}\left\{1+2.5\left(\phi / \phi_{\mathrm{c}}\right) /\left(1-\phi / \phi_{\mathrm{c}}\right)\right\} \\
\mu=\mu_{0}\left(1-\phi / \phi_{\mathrm{c}}\right)^{-2.5}
\end{gathered}
$$

where $\mu_{\mathrm{o}}$ is the viscosity of the liquid in which the spheres are suspended, $\phi$ is the volume fraction of suspended spheres, and $\phi_{\mathrm{c}}$ is the maximum volume fraction of solid particles. The theoretical value of $\phi_{\mathrm{c}}$ is 0.74 for the close packing of spherical particles. For the case of $\phi=0.2, \mu / \mu_{0}=1.92$ and 2.20 are obtained from (10) and (11), respectively. The present experimental value of 2 is consistent with these theoretical values.

\subsection{Effect of Viscosity on Deformation}

Fig. 10 and 11 show the variation of the duration of deformation as a function of viscosity for Duralcan and A356, respectively. The representative viscosity for each specimen was selected as the individual minimum viscosity shown in Fig. 9 with open and filled circles. The filled circles in Figs. 10 and 11 indicate the measured effective duration of deformation. The convex curve drawn as a solid line is the approximated effective duration in Fig. 10 for Duralcan. The effective duration of deformation, which is defined as the time from the beginning of detectable deceleration to the reaching of the zero velocity of the top plate, initially increased and then decreased with decreasing viscosity. The curve shows that the effective duration of deformation reached a maximum at approximately $\mu=32 \mathrm{kPa} \cdot \mathrm{s}\left(\dot{\gamma}=100 \mathrm{~s}^{-1}\right.$ as calculated using (8)). The effective duration of deformation for A356 was increased with increasing viscosity as drawn in Fig. 11 and then the curve profile is different with that for Duralcan.

The viscosity at the maximum effective duration of deformation appeared to be the point at which the dominant factor governing the flow process transitions from plastic forming to viscous flow and vice versa. The cause of the convex profile for Duralcan is qualitatively explained as follows. In a range that exceeded the viscosity at the maximum effective duration of deformation, the top plate impacted the specimen, thereby inducing slight compressive plastic deformation because of the specimen's poor deformability. The experiment was completed within a relatively short duration. A successive reduction in the viscosity, accompanied by an increase in the portion of the melt in the specimen, resulted in an increase in the duration of deformation. Lastly, decreasing the viscosity in the less than the viscosity at the maximum effective duration of deformation made compression easier and again resulted in a decrease in the duration of deformation. The origin of the difference between Fig. 10 for Duralcan and Fig. 11 for A356 is discussed later.

\subsection{Evaluation of Effective Duration of Deformation}

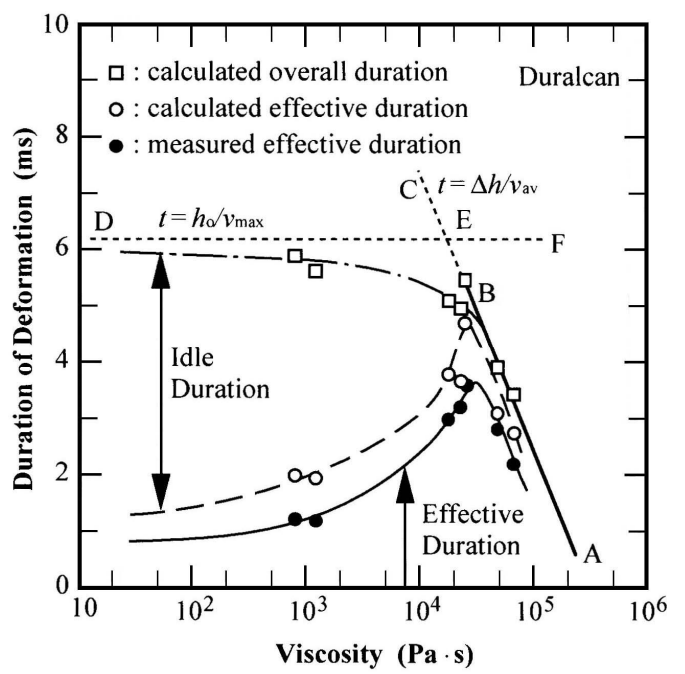

Figure 10. Comparisons of the variations of the measured duration of deformation (solid mark) and the calculated duration (open mark) as a function of the viscosity for the case of Duralcan F3A.20S. Solid, single dotted and broken lines are the approximate lines of filled circles, open squares, and open circles, respectively.

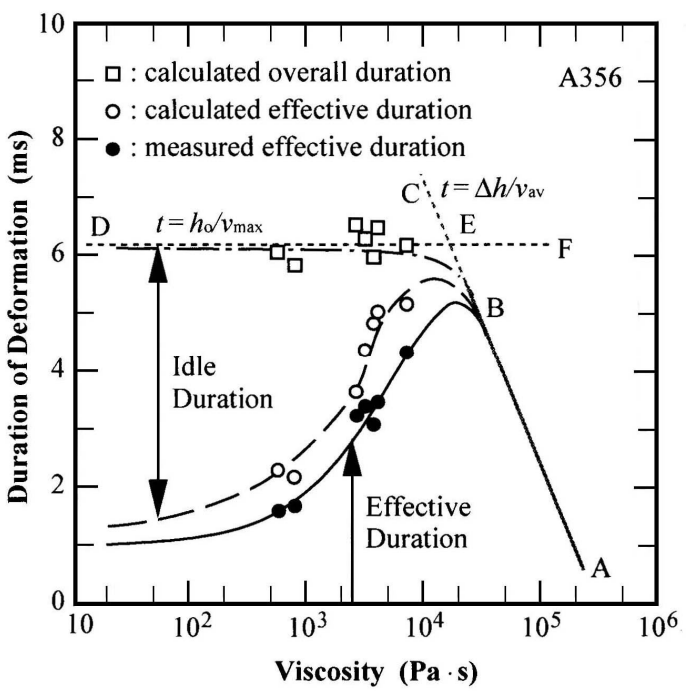

Figure 11. Comparisons of the variations of the measured duration of deformation (solid mark) and the calculated duration (open mark) as a function of the viscosity for the case of the mother aluminum alloy A356. Solid, single dotted and broken lines are the approximate lines of filled circles, open squares, and open circles, respectively.

The process to form the convex curve shown in Fig. 10 for Duralcan was quantitatively discussed on the basis of the deceleration of the top plate. The idealized variation of 
velocity of the top plate as a function of the compression stroke was estimated; the results for Duralcan are shown in Fig. 12. To simplify the analysis, we assumed that the relationship between the falling velocity and compression stroke obeys a linear function, i.e., deceleration is constant and/or no acceleration occurs, and then expressed the results as idealized straight lines, as shown in Fig. 12. The effective duration of deformation initially increased and then decreased; the transition point was $\mu=32 \mathrm{kPa} \cdot \mathrm{s}$ as observed in Fig. 10 . The experimental results were divided into two group: those collected before and after the transition point of $\mu=32 \mathrm{kPa} \cdot \mathrm{s}$. Here, the velocity at the time of contact with a specimen was simply estimated as

$$
v_{\max }=\sqrt{2 g H}=\sqrt{2 \times 9.8 \times 0.3}=2.4(\mathrm{~m} / \mathrm{s})
$$

in the present condition, where the resistance due to friction was ignored. The dotted line $\overline{\mathrm{DF}}$ in Fig. 10 indicates the duration required for a fall of $h_{\mathrm{o}}=15 \mathrm{~mm}$ with a velocity of 2.4 $\mathrm{m} / \mathrm{s}$ (approximately $6.2 \mathrm{~ms}$ ), which was the maximum duration for full compression of the $15 \mathrm{~mm}$-heigh specimens used in this study.

In cases where the viscosity was greater than $32 \mathrm{kPa} \cdot \mathrm{s}$, three specimens ("D, No. 1", "D, No. 2", and "D, No. 3") were considered to follow the velocity change lines of $\overline{\mathrm{OA}}, \overline{\mathrm{OB}}$, and $\overline{\mathrm{OC}}$ in Fig. 12, respectively, and the velocity varied from $v_{\max }=2.4 \mathrm{~m} / \mathrm{s}$ to zero in a short period. The average top velocity of $v_{\max }$ and zero velocity under constant deceleration was calculated as $v_{\mathrm{av}}=1.2 \mathrm{~m} / \mathrm{s}$. In this case, the reduction in specimen height, $\Delta h\left(=h_{0}-h_{\mathrm{a}}\right)$, which was the observed compression stroke, increased as the viscosity decreased. In addition, the average velocity, $v_{\mathrm{av}}$, was equivalent; thus, the effective duration of deformation, $t \quad\left(=\Delta h / v_{\mathrm{av}}\right)$, was proportional to the compression stroke. Moreover, the effective duration of deformation increased with decreasing viscosity. A good agreement between the calculated and experimental results, which are shown by open squares and filled circles in Fig. 10, respectively, were confirmed, and the marks were in accordance with the solid line of $\overline{\mathrm{AB}}$.

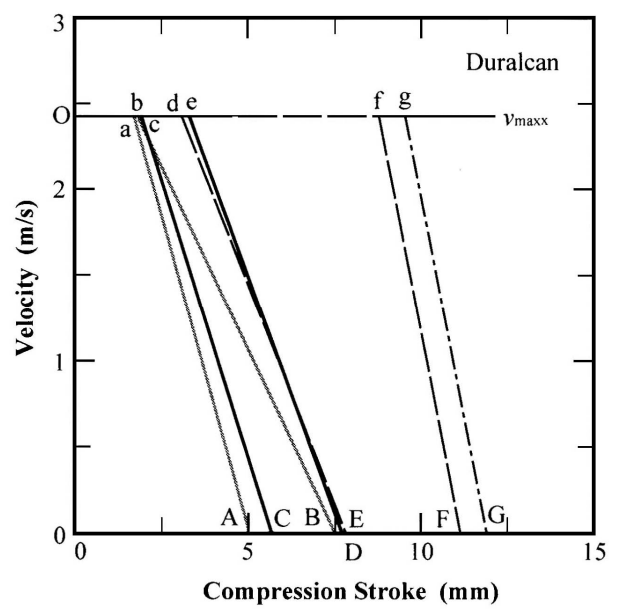

Figure 12. Comparisons of the variation of idealized velocity as a function of the compression stroke for Duralcan.
The viscosity results less than $32 \mathrm{kPa} \cdot \mathrm{s}$ did not follow the dotted line of $\overline{\mathrm{BED}}$ in Fig. 10. In this case, the experimental duration of deformation, i.e., the overall duration of deformation, was considered to be a combination of the idle and effective durations of deformation. The idle duration was the period where detectable deceleration was not observed under the free-fall of the top plate during the compression stroke from $h_{\mathrm{o}}$ to $h_{\mathrm{s}}$, where $h_{\mathrm{s}}$ is the specimen height at the beginning of a detected deceleration of the top plate. This situation is assumed to arise exclusively in the viscosity range of $\mu<32 \mathrm{kPa} \cdot \mathrm{s}$. Based on this assumption, the velocities of top plate in the case of remaining four specimens changed along the paths $\overline{\mathrm{Od}}-\overline{\mathrm{dD}}, \overline{\mathrm{Oe}}-\overline{\mathrm{eE}}, \overline{\mathrm{Of}}-\overline{\mathrm{fF}}$, and $\overline{\mathrm{Og}}-\overline{\mathrm{gG}}$ in Fig. 12 , where the sequences accommodated the descending order of the viscosity. The intervals of $\overline{\mathrm{Od}}, \overline{\mathrm{Oe}}, \overline{\mathrm{Of}}$, and $\overline{\mathrm{Og}}$ correspond to the compression stroke from $h_{\mathrm{o}}$ to $h_{\mathrm{s}}$ that resulted from the period of undetectable deceleration. Those of $\overline{\mathrm{dD}}, \overline{\mathrm{eE}}, \overline{\mathrm{fF}}$, and $\overline{\mathrm{gG}}$ are related to the compression stroke from $h_{\mathrm{s}}$ to $h_{\mathrm{a}}$. The former and latter arose during the idle and effective durations of deformation, respectively. The compression velocities during the idle and effective deformations were assumed to be approximately equal to $v_{\max }$ and $v_{\mathrm{av}}$, respectively. The overall durations are shown by open squares and their fitted line is the single dotted line in Fig. 10. The effective duration of deformation decreased with decreasing viscosity because of the increase in the idle duration. The calculated effective durations shown by open circles are consistent with the measured values as shown in Fig. 10.

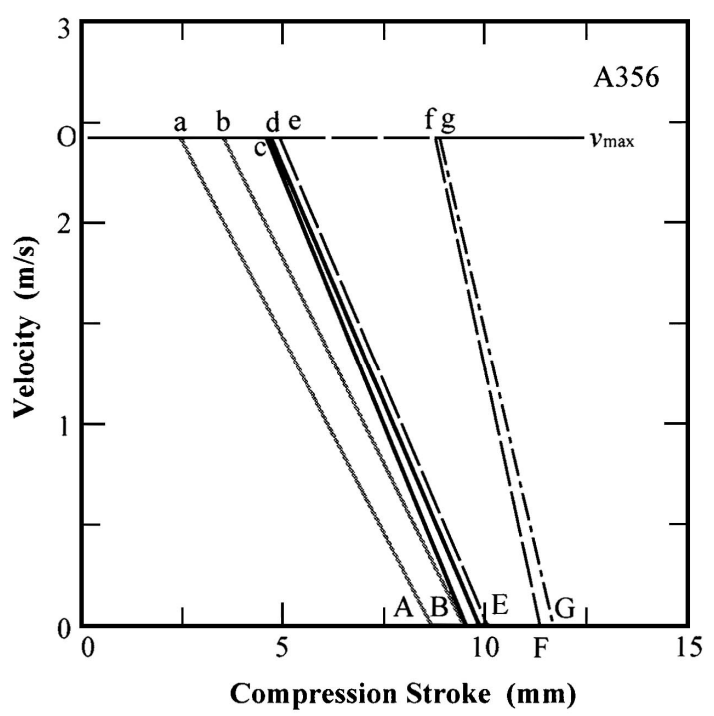

Figure 13. Comparisons of the variation of idealized velocity as a function of the compression stroke for Duralcan's mother aluminum alloy A356.

The idealized variation of velocity of the top plate as a function of the compression stroke for A356 is shown in Fig.13 where the alphabet sequences accommodated the descending order of the viscosity. Fig. 13 showed that the overall duration of deformation was composed of the idle and effective durations of deformation. The calculated and the 
measured effective durations of deformation indicated by open and filled circles, respectively, shown in Fig. 11 are consistent with each other; they exhibited the similar tendency as the results for Duralcan in the viscosity range of $\mu<32$ $\mathrm{kPa} \cdot \mathrm{s}$. Here, we could not observe any results without an idle duration as shown in Fig. 13. The solid line $\overline{\mathrm{AB}}$ in Fig. 11 was drawn at the same position referring to the result for Duralcan illustrated in Fig. 10. No contradiction is observed between estimated solid and broken curves drawn in Fig. 11. Thus we assumed that the effective duration of deformation reached a maximum at approximately $\mu=32 \mathrm{kPa} \cdot \mathrm{s}\left(\dot{\gamma}=63 \mathrm{~s}^{-1}\right.$ as calculated using (9)) and deduced the conclusion that the transition point of Duralcan's mother alloy A356 is appeared to be the same as Duralcan.

\subsection{Estimation of Optimum Forming Condition}

We confirmed that the experimental and calculated interpolation curves, which represent the relationship between the viscosity and effective duration of deformation, quantitatively match as discussed in the previous section. In the region far beyond the transition viscosity, the experiment concludes with a small compression stroke, where the potential energy of the top plate is consumed easily with small deformation of the specimen. The viscosity associated with the longer duration decreases toward the transition point of $\mu$ $=32 \mathrm{kPa} \cdot \mathrm{s}$ until the specimen can no longer consume the kinetic energy without an idle duration in the region below the transition viscosity. Thus, the loss of deformation resistance, accompanied by a decrease in the viscosity, explains the convex curve relationship between the viscosity and the effective duration of deformation. In the present study, the viscosity $\mu=32 \mathrm{kPa} \cdot \mathrm{s}$ was obtained as the point at which the dominant factor governing the visco-plastic flow process transitions from plastic forming to casting and vice versa for both Duralcan and A356.

The semi-solid metal forming process can be considered as intermediate between casting and plastic forming (forging) processes. Therefore, the point of the dominant factor governing the flow process from plastic forming to casting appeared to provide the optimum operating conditions. The conditions must guarantee superior mechanical properties accompanied by fine grains introduced by shear force that arise from the visco-plastic flow of semi-solid material in the mold. If the transition point is expressed as a temperature, it can range from approximately $855 \mathrm{~K}\left(582{ }^{\circ} \mathrm{C}\right)$ to $857 \mathrm{~K}(584$ ${ }^{\circ} \mathrm{C}$ ), which is just above the melting point for both materials. This conclusion is similar to those previously reported for $\mathrm{Al}-\mathrm{Al}_{3} \mathrm{Ni}$ and $\mathrm{Al}-\mathrm{Al}_{3} \mathrm{Fe}$ FGMs [8,9]. To ensure superior mechanical properties of the cast materials, both a moderate working duration and adequate deformation in a high-speed semi-solid forming operation is required. The present experiment was performed using the conditions similar to those applied during commercial production, and the obtained results indicate that the use of a near-net shape forming process for the fabrication of products from $\mathrm{Al}-\mathrm{SiC}$ composite should be possible.

\section{Conclusions}

The present work was carried out to determine the effect of the rheological behavior on the semi-solid formability of an Al-20 vol\% SiC composite of Duralcan F3A.20S and that of the mother aluminum alloy A356 for comparison using a parallel-plate drop-forge viscometer. The effects of applied mass, test temperature, and existence of $\mathrm{SiC}$ particles on viscosity were analyzed and discussed. The results may be summarized as follows:

1. Significant experimental data were obtained in the temperature range from $855 \mathrm{~K}\left(582{ }^{\circ} \mathrm{C}\right)$ to $857 \mathrm{~K}(584$ $\left.{ }^{\circ} \mathrm{C}\right)$. In individual experiments, the observed viscosity was initially decreased as the shear rate increased and subsequently increased as the shear rate decreased. An increase in both the test temperature and the applied force led to a lower viscosity, which resulted in a loss of the ability to resist a deformation.

2. The relationship between the viscosity, $\mu[\mathrm{Pa} \cdot \mathrm{s}]$, and the shear rate, $\dot{\gamma}\left[\mathrm{s}^{-1}\right]$, is described by a power-law model of $\mu=3.2 \times 10^{7} \dot{\gamma}^{1.5}$ for Duralcan and $\mu=1.6 \times 10^{7} \dot{\gamma}^{-1.5}$ for A356. The viscosity of Duralcan is two times greater than that of the mother aluminum alloy depending on the content of $20 \mathrm{vol} \% \mathrm{SiC}$ particles. These results are consistent with the theoretical evaluation of the effect of particles in the suspension.

3. A convex shape curve that reaches a maximum at approximately $\mu=32 \mathrm{kPa} \cdot \mathrm{s}\left(\dot{\gamma}=100 \mathrm{~s}^{-1}\right)$ for Duralcan was observed in the plot of the viscosity as a function of the effective duration of deformation. We quantitatively discussed the origin of the profile by considering the relationship between the idle and effective durations of deformation, and a good agreement between the calculated and experimental results was confirmed.

4. The viscosity of $32 \mathrm{kPa} \cdot \mathrm{s}$ for both Duralcan and A356 correspond to the points at which the flow process dominant factor transitions from plastic forming to casting and vice versa. The transition point appeared to give the optimum condition for near-net shape forming of each material. The optimum operating temperature for both materials ranged from $855 \mathrm{~K}\left(582^{\circ} \mathrm{C}\right)$ to $857 \mathrm{~K}(584$ $\left.{ }^{\circ} \mathrm{C}\right)$, which is just above their melting temperatures.

\section{Acknowledgements}

This research work has been partially support by The Light Metal Educational Foundation Incorporated. We would also like to thank Dr Masayuki Toya, a professor emeritus at Kagoshima University, for many discussions during the course of this work.

\section{References}

[1] M.C. Flemings, R.G. Rieks, and K.P. Young, "Rheocasting", Materials Science and Engineering, Vol.25, pp. 103-117, 1976. 
[2] J.U. Ejiofor, and R.G.Reddy, "Developments in the processing and properties of particulate Al-Si composites", JOM, Vol. 49, No. 11, pp. 31-37, 1997.

[3] V. Laxmanan and M.C. Flemings, "Deformation of Semi-Solid Sn-15 Pct Pb Alloy", Metallurgical Transactions A, Vol.11A, No.12, pp. 1927-1937, 1980.

[4] P.J. Ward, H.V. Atkinson, P.R.G. Anderson, L.G. Elias, B. Garcia, L. Kahlen, and J-M. Rodrigues-Ibabe, "Semi-Solid Processing of Novel MMCs Based on Hypereutectic Aluminum-Silicon Alloys", Acta Metallurgica et Materialia, Vol.44, No.5, pp. 1717-1727, 1996.

[5] H. Iwasaki, T. Mori, M. Mabuchi, and K. Higashi, "Shear Deformation Behavior of Al-5\% Mg in a Semi-Solid State", Acta Metallurgica et Materialia, Vol.46, No.18, pp. 6351-6360, 1998.

[6] J.A. Yurko and M.C. Flemings, "Rheology and Microstructure of Semi-Solid Aluminum Alloys Compressed in the Drop Forge Viscometer", Metallurgical and Materials Transactions A, Vol.33A, No.8, pp. 2737-2746, 2002.

[7] K. Solek, Z. Mitura, R. Kuzaik, and P. Kapranos, "The use of ADINA software to simulate thixocasting processes", Solid State Phenomena, Vols. 116-117, pp. 626-629, 2006.

[8] Y. Fukui, H. Okada, N. Kumazawa, and Y. Watanabe, "Near Net Shape Forming of $\mathrm{Al}_{-} \mathrm{Al}_{3} \mathrm{Ni}$ FGM over Eutectic Melting
Temperature", Metallurgical and Materials Transactions A, Vol. 31A, No. 10, pp. 2627-2636, 2000.

[9] K. Yamagiwa, Y. Watanabe, K. Matsuda, Y. Fukui, and P. Kapranos, "Characteristic of $\mathrm{Al}-\mathrm{Al}_{3} \mathrm{Fe}$ Eco-Functionally Graded Material through Near-Net-Shape Forming over Eutectic Melting Temperature", Materials Science and Engineering A, Vol. A416, Nos. 1-2, pp. 80-91, 2006.

[10] M.C. Flemings, "Behavior of Metal Alloys in the Semisolid State", Metallurgical Transactions A, Vol.22A, No.5, pp. 957-981, 1991.

[11] D.H. Kirkwood, "Semisolid metal processing", International Materials Reviews,Vol.39, pp. 173-189, 1994.

[12] G.J. Dienes and H.F. Klemm, "Theory and Application of the Parallel Plate Plastometer", Journal of Applied Physics, Vol.17, pp. 458-471, 1946.

[13] J.V. Robinson, "The Viscosity of Suspensions of Spheres", The Journal of Physical Chemistry, Vol.53, No.7, pp. 1042-1056, 1949.

[14] M. Mooney, "The viscosity of a concentrated suspension of spherical particles", Journal of Colloid Science, Vol.6, pp. 162-170, 1951. 